\title{
Age at Diagnosis
}

National Cancer Institute

\section{Source}

National Cancer Institute. Age at Diagnosis. NCI Thesaurus. Code C156420.

The age of an individual at the time of initial pathologic diagnosis. 